\title{
Cadê as populações LGBTT na Estratégia Saúde da Família? narrativas de profissionais de saúde em Teresina, Piauí, Brasil
}

\author{
Where are LGBTT populations in the Family Health Strategy? \\ narratives of health professionals in Teresina, Piauí, Brazil
}

Breno de Oliveira Ferreira (https://orcid.org/0000-0002-0979-3911) ${ }^{1}$

Claudia Bonan (https://orcid.org/0000-0001-8695-6828) ${ }^{2}$

${ }^{1}$ Universidade Federal do Amazonas. Av. Gen. Rodrigo Octávio 6200, Coroado. 69080-900 Manaus AM Brasil.

breno.oli@hotmail.com

${ }^{2}$ Instituto Nacional de

Saúde da Mulher, da

Criança e do Adolescente

Fernandes Figueira,

Fundação Oswaldo Cruz.

Rio de Janeiro RJ Brasil.

\begin{abstract}
The populations of lesbians, gays, bisexuals, transvestites, and transsexuals (LGBTT) have not had a place in the "official history" of humanity, except as secondary actors that deviate, distort, or even tarnish popular memory, guided by cisheteronormativity. These same subjects often experience obstacles in the care provided by the Family Health Strategy (ESF) within a universal, comprehensive, and equitable system. This paper seeks to analyze experiences narrated by primary care professionals in health care for LGBTT populations in Teresina, Piaui, Brazil. This is qualitative research conducted with 32 professionals working at a PHC unit. The analysis was based on three dimensions - relational, organizational, and contextual - inspired by the Giovanella and Fleury theoretical discussion. Primary care, which should be one of those responsible for community health actions and prioritize health promotion and prevention, is the same that has provided denials, violence, and neglect in the care of LGBTT people. Therefore, we selected listening as one of the keys to respecting sexual and gender diversity so that these people are recognized as ESF users. Key words Sexual and gender minorities, Health professionals, Primary Care, Health care
\end{abstract}

Resumo As populações de lésbicas, gays, bissexuais, travestis e transexuais (LGBTT) não têm tido um lugar na "história oficial" da humanidade, a não ser como atores secundários que desviam, distorcem ou mesmo maculam a memória dos povos, orientada pela cis-heteronormatividade. São esses mesmos sujeitos que frequentemente vivenciam obstáculos na assistência ofertada pela Estratégia Saúde da Família (ESF), dentro de um sistema que é universal, integral e equânime. Neste artigo, buscamos analisar experiências narradas por profissionais da atenção básica na assistência à saúde das populações LGBTT em Teresina, Piauí, Brasil. Trata-se de uma pesquisa qualitativa realizada com 32 profissionais que atuavam em uma unidade básica de saúde. A análise foi pautada em três dimensões - relacional, organizacional e contextual - inspirada na discussão teórica de Giovanella e Fleury. A atenção básica, a qual deveria ser uma das responsáveis pelas ações de saúde comunitária, que prioriza a promoção e a prevenção em saúde, é a mesma que tem ofertado negações, violências, e negligência no cuidado às pessoas LGBTT. Aposta-se, portanto, na escuta como uma das chaves para o respeito à diversidade sexual e de gênero, para que essas pessoas sejam, assim, reconhecidas como usuárias da ESF.

Palavras-chave Minorias sexuais e de gênero, Profissionais de saúde, Atenção Básica, Assistência à saúde 


\section{Introdução}

No Brasil como um todo, e especialmente no estado do Piauí, a violência contra as populações LGBTT (lésbicas, gays, bissexuais, travestis e transexuais) expressa e quantificada em relatórios é assustadora. Em 2017, os dados coletados pelo Grupo Gay da Bahia (GGB), que são divulgados anualmente no relatório de mortes dessas populações, apontaram que, a cada 19 horas, uma pessoa LGBTT é morta ou se suicida no Brasil, o que faz do país o campeão mundial de crimes contra as minorias sexuais e de gênero. O número de violências contra essas populações chegou a ser três vezes maior do que o observado há dez anos, e as pessoas trans foram consideradas como de maior risco de morte ${ }^{1}$.

Os dados do mesmo relatório divulgados em 2015 mostraram que, em termos relativos, o estado Piaú foi identificado com o segundo lugar que mais oferece risco de pessoas LGBTT serem violentamente mortas. Já no balanço dos dados do Disque 100 em 2018, o estado do Piauí ficou em terceira posição ${ }^{2}$. Paradoxalmente, é conhecido no cenário nacional pelo pioneirismo na elaboração de leis e normativas de proteção às populações LGBTT.

Contudo, como a Estratégia Saúde da Família (ESF) tem contribuído para a melhoria de indicadores de violência contra as populações LGBTT no estado? Ou melhor, como os profissionais da atenção básica têm cuidado das populações LGBTT em Teresina, Piauí? Partindo de uma compreensão de saúde a partir da determinação social, situamos a orientação sexual e a identidade de gênero daqueles que escapam ao binarismo sexual como condicionantes/determinantes de saúde. Fontes de estigmas e preconceitos, esses sujeitos são expostos a inúmeras situações de discriminações, negações, embarreiramentos e interditos desde o acesso à assistência propriamente dita nos diversos serviços da rede ${ }^{3}$.

A produção de saúde das populações LGBTT pode estar comprometida por inúmeras condições: os modos de viver construídos por esses sujeitos - muitas vezes, como estratégias de sobrevivência, resistência e enfrentamento -, que podem acabar se materializando em práticas corporais e sexuais que os expõem ao adoecimento; a pouca motivação para a busca dos serviços de saúde devido a receios, histórias pregressas ou histórias de terceiros de julgamentos, maus-tratos e outros constrangimentos; a pouca reflexão e conhecimento dos profissionais sobre questões da saúde LGBTT; além de situações de pobreza e outras precariedades que podem dificultar o acesso aos serviços e a efetividade da assistência à saúde ${ }^{4-6}$.

O cuidado em saúde sexual e reprodutiva é uma das áreas de atuação prioritária da atenção básica, e, portanto, o Ministério da Saúde vem atuando em diversos eixos para assegurar que as políticas de saúde estejam em consonância com as diretrizes de promoção da igualdade sexual e de gênero ${ }^{7}$. Várias ações vêm sendo desenvolvidas no sentido de buscar concretizar o próprio princípio da equidade no Sistema Único de Saúde (SUS).

Em parceria com representantes do movimento social LGBTT, em dezembro de 2011, foi aprovada a Política Nacional de Saúde Integral de Lésbicas, Gays, Bissexuais, Travestis e Transexuais, que tem, entre seus objetivos, a proposta de eliminar a discriminação e o preconceito institucional, bem como contribuir para a redução das desigualdades e a consolidação do SUS como sistema universal, integral e equitativo em todo o país 8 .

Em Teresina, os serviços de cobertura em saúde iniciaram em meados de 1994, quando a cidade reestruturou seu modelo assistencial de forma a atender os princípios doutrinários do SUS, o que resultou na incorporação do Programa de Agentes Comunitários de Saúde (PACS). Dois anos depois, o Conselho Municipal de Saúde aprovou a implantação do Programa Saúde da Família (PSF), que inicialmente passou a ser desenvolvido por três equipes. Em 1998, já composto por 40 equipes, o programa cobria um terço da população do município 9

Hoje o município de Teresina tem cobertura completa da ESF, possui uma rede formada por 90 unidades básicas de saúde (UBS), incluindo aquelas rurais e urbanas, e 37 equipes com adesão ao Programa de Melhoria do Acesso e Qualidade da Atenção Básica (PMAQ-AB). Possui também três equipes de Núcleo Ampliado de Saúde da Família e Atenção Básica (Nasf-AB), e uma de Consultório na Rua (eCR) ${ }^{9}$. Mesmo com a elevada cobertura populacional e um modo próprio de corresponsabilidade sanitária na operacionalização da ESF, não há garantias de que as estratégias desenhadas e pactuadas nas políticas e programas se efetivem no cuidado às pessoas LGBTT nas unidades básicas de saúde (UBS).

Somado a isso, o trabalho na atenção básica, além de dimensões técnica, econômica, política e ideológica, envolve um componente ético essencial vinculado à emancipação das pessoas e das famílias ${ }^{10}$. Se o vínculo usuário-profissional 
é fortalecido, por exemplo, a revelação da orientação sexual e/ou identidade de gênero se torna como natural durante os atendimentos ${ }^{3}$.

No entanto, sabemos que as transformações positivas que ocorreram ao longo dos anos e foram incorporadas na construção da ESF, não implicam diretamente em uma mudança nas práticas dos profissionais de saúde, fazendo-se necessário problematizar o fazer em saúde como um todo, principalmente frente aos retrocessos presentes na última atualização da Política Nacional de Atenção Básica de $2017^{11}$. Dessa forma, este artigo buscou analisar experiências narradas por profissionais da atenção básica na assistência à saúde das populações LGBTT em Teresina, capital do estado do Piauí.

\section{Percurso metodológico}

Trata-se de uma pesquisa de abordagem qualitativa em que o método escolhido foi o estudo de narrativas ${ }^{12}$. Para tanto, foi escolhida uma UBS situada em região central de Teresina e que conta com seis equipes de saúde da família (eSF) e uma equipe de Consultório na Rua (eCR), além de ter articulação com equipes de Núcleo Ampliado de Saúde da Família e Atenção Básica (Nasf-AB). Pela sua dimensionalidade, é considerada Tipo II pelo Ministério da Saúde e conta com coordenação local.

Participaram da pesquisa trinta e dois profissionais de saúde. Como critérios de inclusão, selecionamos médicos, enfermeiros, cirurgiõesdentistas, técnicos e/ou auxiliares de saúde bucal, técnicos e/ou auxiliares em enfermagem, agentes comunitários de saúde (ACS) e coordenador, além de profissionais que integravam as equipes de Nasf-AB (psicólogo, fisioterapeuta e nutricionista) e aqueles da eCR (enfermeiro, assistente social, médico e agente social). Todos atuavam há, pelo menos, seis meses na atenção básica. Foram excluídos aqueles que estavam afastados por motivos de licença, capacitações ou treinamentos. Também adotamos o debate sobre amostragem e saturação de Minayo ${ }^{13}$, e a coleta de dados, que ocorreu entre agosto e outubro de 2019, foi interrompida quando as narrativas se mostraram repetitivas.

Para ter acesso às narrativas dos profissionais, utilizamos a entrevista individual narrativa ${ }^{12}$, que, por meio de uma forma elementar de comunicação, buscou encorajar vinte e seis participantes a contar histórias sobre acontecimentos e experiências profissionais. Também foi realizado um grupo focal ${ }^{14}$ com mais seis participantes a fim de compreender as práticas cotidianas, representações e simbologias dentro do grupo de profissionais.

Para a construção do enredo, seguimos a proposta de Gomes e Mendonça ${ }^{15}$ que, em termos de sequência analítico-interpretativa, traçam algumas fases essenciais: (1) compreensão do contexto das narrativas; (2) desvendamento dos aspectos estruturais das narrativas; (3) síntese interpretativa das narrativas. A análise qualitativa foi pautada em três dimensões - relacional, organizacional e contextual - inspirada na discussão teórica de Giovanella e Fleury ${ }^{16}$.

No que tange aos procedimentos éticos, a pesquisa foi aprovada pelo comitê de ética do Instituto Nacional de Saúde da Mulher, da Criança e do Adolescente Fernandes Figueira (IFF), da Fundação Oswaldo Cruz (Fiocruz), em julho de 2019. Todos os sujeitos envolvidos foram orientados a assinar o Termo de Consentimento Livre e Esclarecido (TCLE) e os nomes reais dos participantes foram alterados por nomes fictícios.

\section{Resultados e discussão}

A maioria dos sujeitos tratava-se de mulheres (83\%), o que nos fez, a partir deste ponto, escrever este artigo na gramática política do feminismo, generalizando e expandindo para o feminino-plural. $48 \%$ tinha idade entre $40-60$ anos, a média foi de 16 anos de tempo de trabalho dentro da categoria profissional, e 19 anos de atuação na atenção básica. $42 \%$ possuíam algum curso latu sensu, preferencialmente em saúde pública, saúde da família ou saúde mental, e $3 \%$ possuíam mestrado e/ou doutorado. Daquelas que trabalhavam em cargos de nível médio, 30\% já possuíam graduação ou estavam cursando. A cisgeneridade foi um ponto em comum a todas as participantes e $94 \%$ se identificou como heterossexual, dividindo-se entre solteiras $(50 \%)$ ou casadas $(50 \%)$, $60 \%$ se declarou negra, e $65 \%$ católica.

O que esperar desse universo de mulheres cis, heterossexuais, na meia-idade, com vários cursos de capacitações, casadas ou solteiras, predominantemente negras e de base católica? A partir de debates teóricos consolidados por Giovanella e Fleury ${ }^{16}$, neste artigo, as experiências das profissionais serão apresentadas em três dimensões principais: relacional, que diz respeito às relações intersubjetivas entre usuários e profissionais; organizacional, que se refere aos modos de organizar os serviços e os processos de trabalho; e, 
por fim, contextual, que engloba os modos como situações de vulnerabilidade e determinantes sociais afetam as condições de satisfação das necessidades de saúde. A distinção entre essas dimensões é meramente para fins de operacionalizar a análise, entretanto, nos fluxos de interação da vida real elas são imbricadas.

\section{Dimensão relacional}

A questão de saber/conhecer sobre a identidade de gênero e/ou a orientação sexual foi apontada na retórica das profissionais como algo "pouco relevante" para o atendimento em saúde. Com esse discurso, de algum modo, se nega, se interdita ou se embarreira o processo de revelação em si, seja espontânea, como autorrevelação, seja a partir da pergunta pela profissional de saúde. O curso da comunicação usuário-profissional deveria ser um momento de construção de confiança, de troca de saberes, de compaixão, de solidariedade e reconhecimento dos sujeitos e de suas singularidades ${ }^{6,17}$. Porém, se ao usuário não é permitido sair do armário no fluxo de suas interações no atendimento, por vias tortas, pelas brechas da porta, as profissionais parecem interessadas em localizar e reiterar o lugar das pessoas LGBTT ali, no armário. Ao invés de perguntar ou dialogar, a trilha parece seguir outra cadeia de descoberta. Parece-nos um quebra-cabeça, com algumas peças que são montadas, outras ocultadas, até que se conclua algo sobre a questão:

Vou definir Teresina como uma provincia. As pessoas têm muito medo de se assumir, tanto é que como eu trabalho na mesma área que eu moro, tem pessoas que eu sei que são LGBTT, mas elas simplesmente não falam, só sei porque moro ali. (Manuela, ACS)

Muitas vezes, quem informa pra gente são pessoas próximas deles. Muitas vezes é um vizinho, é uma pessoa que mora na rua, ou um conhecido dele. (Josefa, téc. em enfermagem)

Não, acho que não [deve perguntar sobre orientação sexual e identidade de gênero], eu acho que é irrelevante. Eu considero que seja importante a questão dessa categoria, mas não, não considero relevante perguntar. Muitas vezes é o ACS que traz a informação, eu mesmo não costumo fazer esse tipo de pergunta, e fica tudo bom. (Marta, enfermeira)

Manuela, que é uma agente comunitária de saúde (ACS) e mora na região na qual trabalha, acaba se utilizando das redes informais e cotidianas para conhecer sobre as questões de orientação sexual e identidade de gênero das pessoas usuárias. Às vezes, assim como lembrou Josefa, essa informação transpassa a rede dos consultórios, e pode chegar através de um vizinho. A abertura da porta que permite vislumbrar o interior do armário é, mais uma vez, intermediada por um terceiro na relação.

Percebe-se uma tendência em manter as populações LGBTT no âmbito da suspeita, da dúvida, da curiosidade. Ao mesmo tempo em que criam uma espécie de interdito sobre o assunto, principalmente quando evitam perguntar sobre essas questões, podem culpabilizar o usuário por não verbalizar sua orientação sexual e/ou identidade de gênero durante o atendimento - "mas ele também não me diz!” (Marcos, médico). Com isso, as profissionais negam qualquer tipo de discriminação (no estilo de pensamento que preconiza que não reconhecer as diferenças significa diretamente não discriminar), e reafirmam a ética de "atender todo mundo do mesmo jeito" (Cristiane, enfermeira).

A perspectiva de sair do armário também foi associada principalmente aos gays considerados afeminados, aqueles que notadamente possuem, aos olhos das profissionais de saúde, alguma performance destoante do que se espera de uma performance masculina, por exemplo. E alguns elementos entram nesse quebra-cabeça, como o "jeito", as vestimentas, a voz e outros. Camila, enfermeira, narrou que "o comportamento, o jeito, a voz, já diz tudo, não precisa nem a gente perguntar".

Essa estratégia de espreitar o armário dos sujeitos que escapam às formas de se conceber as feminilidades e as masculinidades, especialmente entre gays e lésbicas, parece ter uma lógica diferente de travestis e transexuais. Na perspectiva das profissionais de saúde, para os gays e lésbicas, há uma busca de classificação da orientação sexual a partir de estereótipos, moralidades e julgamentos próprios, impregnados de senso comum. Esse dispositivo que não permite por completo nem uma visibilização afirmativa nem uma ocultação defensiva pode ser, ainda, uma estratégia de regulação e controle social dos corpos dissidentes ${ }^{18}$. Muitas vezes, esses sujeitos - populações L, G e B - possivelmente tentam corresponder a padrões, a fim de que sejam melhor recebidos e atendidos nos serviços de saúde, conforme apontaram alguns estudos ${ }^{3,6,19}$.

Para as pessoas travestis e transexuais, que já trazem em si outras formas de expressões de suas corporalidades, o quebra-cabeça parece já estar montado. A enfermeira Clara relatou o uso do nome social por travestis e transexuais como um elemento importante na conformação das iden- 
tidades dissidentes, e que retira esses sujeitos do âmbito da suspeita e da curiosidade, como ocorre com lésbicas e gays, e os nomeiam enquanto travestis e transexuais:

Quem é travesti? Dá pra perceber rápido, tem a questão do nome social. Os outros até tenho mais dúvidas, mas esses não. (Clara, cirurgiã-dentista)

A unidade de saúde, como um espaço que deveria ser de circulação livre, constitui-se de relações diferentes entre os vários sujeitos da sopa de letrinhas, o que dá origem a uma experiência de espacialidade marcada por regras e normas muito distintas. As corporalidades aceitáveis são aquelas que "passam" sem serem reconhecidas pela não cisgeneridade e pela não heteronormatividade. Não ser identificado como LGBTT nos atendimentos, nos faz pensar na noção de "passabilidade", que pode ser uma estratégia de esquiva ante as discriminações e violências que podem ocorrer nos serviços de saúde. Alguns sujeitos "passam" mais facilmente que outros, ou seja, dentro da sopa de letrinhas, alguns sujeitos têm, mais do que outros, o privilégio de passar despercebidos em sua orientação sexual e/ou identidade de gênero.

\section{A dimensão organizacional}

$\mathrm{O}$ princípio de equidade surgiu em meio ao período contemporâneo, promovendo associações aos direitos das minorias. Teve a intenção de introduzir a diferença no espaço público da cidadania, que atua no cerne da luta pelas diferentes igualdades. Com isso, o reconhecimento da diferença entra em conflito com o pensamento jurídico clássico que percebe a cidadania como sendo comum e indiferenciada. Não obstante, diante da diversidade das sociedades modernas, a perspectiva de igualdade só se completa quando compartilhada com a própria noção de equidade. Não basta um padrão universal se este não comportar o direito à diferença. Não se trata mais de um padrão homogêneo, mas de um padrão equâni$\mathrm{me}^{10,20}$. Para as profissionais de saúde entrevistadas, a ideia de equidade que deveria reger a organização do trabalho junto às populações LGBTT parecia ser distorcida, conforme relatos abaixo:

Eu atendo todos os pacientes do mesmo jeito, com a mesma equidade, a mesma simpatia, eu tento dar tudo de mim, eu faço com amor. Você viu oh, os pacientes aqui do consultório, todos sairam satisfeitos, alguém saiu aqui me xingando? Ninguém me chamou de enfermeira ruim, entendeu? (Cristiane, enfermeira)

Grupos específicos, pra mim, eu penso em patologias, por exemplo, grupo de hipertensos. Tem os diabéticos que a gente vai tratar aquela doença específica ali, mas aí você tratar um grupo específico de forma diferenciada só porque é aquele grupo ali, não, eu acho que tem que ter equidade, independente da condição sexual. (Conceição, médica)

$O$ atendimento em si, no consultório, foi feito da mesma forma que é feito com outro paciente, sem nenhum tipo de diferenciação, seguindo a mesma equidade. (Pedro, auxiliar de saúde bucal)

Os recortes de Cristiane, Conceição e Pedro exemplificam como o conceito de equidade parece ser subsumido ao de universalidade, outro princípio do SUS. Não é porque o sistema é de todos que todos têm as mesmas necessidades e demandas no que diz respeito aos cuidados de saúde ${ }^{10}$. Foi por isso mesmo que o conceito de equidade foi proposto, justamente para incluir as diferenças no campo do cuidado em saúde ${ }^{20}$. Cristiane, além de distorcer esse conceito, ainda avalia o seu atendimento pela falta de "explosividade" do usuário. Em sua fala, parece existir um projeto humanitário, baseado no amor, como ela mesma cita, mas que acaba por invisibilizar as especificidades de cuidado do outro. O outro, que é evocado pelo amor, quando parece não se rebelar, é mencionado, citado e lembrado. Por isso mesmo que muitos usuários LGBTT têm dificuldades de revelar suas identidades dissidentes, pela padronização do atendimento que deveria ser singularizado e construído a partir de vínculos, troca de saberes e respeito $^{4,6}$. Conceição foi bem objetiva, enquadrando a patologia como essencial na rotina médica, talvez na tentativa de se afastar de outros conteúdos que não considera importante para o trabalho em saúde. E é assim que Pedro também acredita, que todos devem receber os mesmos cuidados. $\mathrm{E}$ já que o trabalho segue em equipe, as concepções parecem seguir compartilhadas.

Reiteramos o quanto a clínica da atenção básica ainda parece estar fortemente centrada na abordagem biomédica ${ }^{10}$, e isso dificulta a passagem para o trabalho longitudinal, em rede, ampliado, e que compreende os sujeitos entre as esferas biopsicossociais da vida, corroborando com os achados em outros estudos ${ }^{5,6}$.

Quando perguntados sobre legislações, políticas, e/ou resoluções no campo da saúde das populações LGBTT, a negativa veio em coro: "Não, não conheço. $\mathrm{O}$ protocolo que a gente usa fala basicamente só de doenças sexualmente transmissíveis" (Marta, enfermeira); "Ficou o ponto de interrogação" (Clara, auxiliar em saúde bucal); “Não, tu acreditas que não?” (Manuela, ACS).

Já durante o grupo focal, as ACS afirmaram não perguntar sobre essas questões durante o 
preenchimento na ficha E-SUS, por não elegerem como importantes para a rotina de trabalho, conforme transcrições: "Eu boto tudo hétero!" (Letícia, ACS); "A questão é que a gente não leva ao pé da letra essas duas perguntas do cadastro individual, só que eu tô vendo agora assim, como um erro, porque se tem a gente tinha que perguntar, né?" (Flávia, ACS - grifos nossos).

$\mathrm{Na}$ ficha do E-SUS existem duas perguntas sobre orientação sexual e identidade de gênero, que não são consideradas de cunho obrigatório pelo sistema: "Você deseja informar a sua orientação sexual/identidade de gênero?" $\mathrm{O}$ usuário pode responder que "sim" ou que "não". Em caso positivo para a orientação sexual, pode optar entre "heterossexual, bissexual, homossexual (gay ou lésbica) ou outra". Em caso positivo para a identidade de gênero, pode optar por "homem transexual, mulher transexual, travesti ou outra".

A partir desse diálogo no grupo, percebemos que $\mathrm{o}$ ato de preencher o formulário com a orientação heterossexual para todos, como trouxe Letícia, principalmente sem consulta prévia, reforça os padrões heteronormativos dentro dos serviços de saúde, e revela ainda o despreparo não só das profissionais agentes comunitárias, mas da equipe como um todo. Flávia ainda ressalta que essas questões não são "levadas ao pé da letra". Nessa trama, as populações LGBTT continuam ocultadas, embarreiradas e negadas dentro dos serviços da unidade estudada. Portanto, nos questionamos se havia tido alguma iniciativa de capacitação ou treinamento ofertado pela gestão, ou por iniciativas das próprias profissionais. $\mathrm{E}$ a resposta também seguiu a cascata de nãos: "Não. Eles não dão nada de esclarecimentos sobre isso, só teve um de teste de Aids." (Catarina, téc. em enfermagem); "Eu não sei, não lembro." (Suzana, ACS); "Não, pelo menos nessa unidade aqui, eu nunca vi, com relação a tuberculose, hanseníase, vacinas, essas coisas." (Josefa, téc. em enfermagem).

Ao longo das narrativas, nenhuma profissional de saúde elencou algum curso com enfoque na saúde das populações LGBTT, seja antes ou depois da implantação da política. Os treinamentos e cursos de capacitação e atualização, para elas, pareciam se inscrever na ordem do saber biomédico (tuberculose, hanseníase, vacinas, etc.) ou quando, por casualidade, tocam a questão LGBTT, se volta à velha e tão constante discussão da Aids. Entre os muitos nãos - "não tive", "não conheço", "não sei" - aparece também o "não lembro", aquela ausência que nem a memória consegue registrar. Destacamos também que não apareceram cursos com temáticas como direitos humanos, diversidade sexual, violência e gênero, e outras afins, o que nos faz pensar que os cursos voltados para saúde LGBTT não geram interesse por parte de diferentes atores desse cenário.

\section{A dimensão contextual}

As violências não se constituem como uma entidade, como um fenômeno uniforme, monolítico, que se abate sobre a sociedade como algo que lhe é exterior e pode ser explicado através de relações do tipo causa e efeito ${ }^{21}$. Ao contrário, as narrativas das profissionais de saúde mostraram como a violência estrutural é mascarada, multifacetada, e se encontra diluída em meio à sociedade sob as brumas das mais diversas manifestações, que se interligam, interagem, (re)alimentam e se fortalecem. Patrícia preferiu chamar de "combo" esses elementos que se intermeiam no contexto das vulnerabilidades que amplificam a violência: "Quando o paciente vem pra gente, vem com um combo. É de situação de rua, HIV, negro, tuberculose, pobreza, dificuldade. É tanta coisa que é difícil, a violência fica escancarada" (Patrícia, assistente social - grifo dos autores).

O relato de Patrícia mostra como temos marcas de uma sociedade em crise: econômica, ética, cultural, de identidade, de pertencimento, da saúde, da educação e tantas outras². E as inúmeras diferenças e assimetrias de poder geradas em meio a essas crises são reencenadas em desigualdades que acabam por reforçar as relações de opressão na sociedade. E o outro, que aqui carrega um "combo", não é reconhecido como sujeito, quiçá como sujeito de direitos. Como pensar as subjetividades e alteridades desses sujeitos em meio a esse contexto tão desigual? Apesar de parecer óbvia essa pergunta, as situações e condições socioeconômicas que inspiram a violência estrutural devem ser encontradas na própria estrutura da sociedade. Se a crise é múltipla, Arruza et al..$^{22}$ afirmam que precisamos de um "combo" de enfrentamentos, próprio para cada cultura, gestado a partir de práticas solidárias, colaborativas, coletivas e complementares. Essas práticas podem ser capazes de estruturar as noções de poder e direcionar para uma igualdade política, social e econômica. Caio, que é gay, parece ter um olhar bem crítico sobre o que vê e percebe, e inclui elementos específicos da cultura nordestina nessa produção de desigualdades.

Tem muitas pessoas do Sul que não gostam de quem é do Nordeste porque acham que a gente come calango, é pobre, passa fome, é negro. É uma segregação dentro da segregação e tudo isso vai es- 
tar ligado na hora que chegar nos LGBTT. (Caio, téc. em enfermagem)

As construções imagéticas do povo nordestino sempre estiveram desenhadas na história do Brasil, entre livros, mitos e lendas. Mostram as disputas por terras, a miséria, a fome e o desejo de justiça (contado pelo grupo de Lampião e os seguidores do messiânico Antônio Conselheiro que afrontavam o poder local). Como consequência, ficou para os nordestinos a construção de estereótipos de miserável, pobre, sem-terra, justiceiro e diversos outros ${ }^{23}$. Esses se perpetuaram e se perpetuam até hoje no imaginário de alguns, principalmente aqueles que moram no Sul e Sudeste do país. Mas mesmo dentro dos diferentes nordestes, existem outras segregações, outras enredagens que circulam por meio de relações assimétricas de poder dentro do mesmo território geográfico e cultural. E elas não podem passar desapercebidas, conforme Caio trouxe em seu relato.

Nesse cenário de elementos sociais e culturais, também é importante problematizar sobre as crenças religiosas enquanto questões que chegam até a unidade e que influenciam nos processos de trabalho das profissionais de saúde junto às populações LGBTT. Por isso buscamos entender como essas profissionais as concebem, interpretam e agem na dinâmica da assistência.

Mas tu sabes como é aqui no Piauí, a religião é muito forte. A pressão de ser de uma religião e de outra, isso influencia muito (...) já vi cada cena aqui na unidade. Cada fala de colegas de trabalho. Nunca esqueço de uma mulher que ficou forçando a entrega de um panfleto desses de igreja para uma pessoa que se vestia assim. (Joana, cirurgiã-dentista)

A onda do fundamentalismo religioso que assola não só o Brasil, mas outros países latino -americanos, tem produzido formas de negação, discriminação, apagamento e retrocesso no campo dos direitos humanos. Estudo ${ }^{24}$ mostra que muitas profissionais da atenção básica descrevem a cisgeneridade e a heterossexualidade como verdadeiras "vontades divinas", e, portanto, as populações LGBTT estariam descumprindo uma determinação sagrada. As representações sociais dessas profissionais parecem enquadrar todas as formas de identidade que subvertem a cis-heteronormatividade enquanto pecado, podendo levar a comportamentos discriminatórios em diferentes âmbitos, mesmo sem a percepção consciente das pessoas que as concebem e praticam ${ }^{24}$.

As cenas de violências estão face a face com o cotidiano de trabalho na unidade. As profissio- nais relataram várias outras situações com colegas da unidade que, de forma muito grave, chegaram a negar atendimento às populações LGBTT. Os moralismos profissionais parecem se revestir de recusa, quebra de códigos de ética, desrespeito à Constiuição Federal, descuido e negligência. Mas o SUS não é de todos? Depende, principalmenre da orientação sexual e identiadade de gênero. Estes mostraram que os marcadores de gênero fragilizam o acesso e a qualiadade da assistência à saúde, podendo afastar ainda mais as populações LGBTT da ESF. E onde essas pessoas vão encontrar cuidado? Elas retornam à unidade? Estudos recentes ${ }^{5,6}$ mostraram que as populações LGBTT acabam tendo o seu direito de acesso à saúde violado, naturalizando um "não lugar” no SUS, levando a outras rotas precárias de assistência à saúde.

Essas formas de violências também ocorrem em meio a outras, como a violência simbólica, discutida por Bourdieu ${ }^{25}$. Para o autor, ela é "censurada e eufemizada, isto é, desconhecida e reconhecida" 25 (p.211). Nos relatos, ela aparece como um modo de dominação nos contextos em que não se exerce controle diretamente. Diferentemente dos casos em que se deixa de anteder o usuário LGBTT - "Eu não atendo gay aqui, eu já disse isso, e ponto" (Antônio, médico) - a violência simbólica se instaura, por exemplo, com "as piadinhas", conforme cita Pedro: "a gente vê umas risadas de canto, piadinhas, aqui mesmo na sala de espera" (Pedro, auxiliar de saúde bucal). A ideia de que a LGBTfobia tem relação com o controle social dos corpos é como uma espécie de patrulhamento cotidiano das (in)conformidades de gênero. As formas de violências incluem um emaranhado de discursos, práticas culturais, sociais e políticas produzidas ${ }^{18}$.

As iniquidades de gênero se tornaram ainda mais potenciadas em meio às desigualdades econômicas, geográficas, políticas e sociais do país. O contexto brasileiro, o contexto nordestino e o contexto piauiense se mostraram permeados de gatilhos de violências, negações e apagamentos, quando em si mesmo já não representam a violência nua e crua. Quando voltamos nossas lentes para a unidade, desde a forma mais "sorridente" de falar com o usuário, até a negação de um atendimento, as violências que ali se tecem interferem diretamente na qualidade da assistência prestada às populações LGBTT. O discurso das profissionais mostrou o quanto as violências acontecem nesse terreno que deveria ser de proteção e cuidado, e o quanto essas cenas são partilhadas. $\mathrm{Ou}$ seja, o processo de determinação social em saúde 
se traduz em condições materiais, psicológicas, culturais, morais, jurídicas e políticas que privam as populações LGBTT, em graus diferentes, de direitos, autonomia e participação, e as excluem dos variados recursos disponíveis na rede de saúde ${ }^{4-6}$.

\section{Considerações finais}

Essas elucubrações enunciam que as populações LGBTT não são reconhecidas como "população em geral" - como prescreve a própria Política Nacional de Atenção Básica de 2017 -, nem são reconhecidas como populações que demandam cuidados específicos de saúde. Portanto, não se trata de reflexões para que as populações "se sintam normais" nos atendimentos na ESF, como atestam alguns relatos, mas, pelo contrário, que sejam reconhecidas em suas próprias diferenças, e que suas expressões, desejos, identidades e corporalidades possam ser acolhidas e respeitadas nos territórios. Pelo visto, essas diferenças têm sido apagadas, ocultadas e embarreiradas pelo discurso da normatividade, a favor de uma suposta igualdade, que opera ainda mais nas linhas de discriminações e violências em saúde.

$\mathrm{Na}$ dimensão relacional, percebeu-se o quanto a revelação da orientação sexual/identidade de gênero é ao mesmo tempo espreitada pelas profissionais de saúde, quando fica no âmbito da suspeita, como também é interditada, quando não se pergunta, não se quer perguntar e nem se registra, seja no âmbito da comunicação com o usuário, seja nas fichas, prontuários e cadastros de trabalho. Na dimensão organizacional, notou-se que a maioria das profissionais não conhecem a Política Nacional de Saúde LGBTT. É claro que conhecer sobre a política não garante a qualidade de um atendimento. Contudo, chama-nos atenção que algumas justificativas são postas na ordem do não saber, do não contato na formação e da não iniciativa da gestão. Ao analisar alguns elementos contextuais que poderiam interferir na dinâmica de trabalho e nas práticas em saúde na unidade, as profissionais narraram casos de negligência, quebra de sigilo e confidencialidade, recusa no atendimento e violências simbólicas, expressas nos sorrisos, nas piadinhas e nos julgamentos morais e religiosos. Na ESF, os "anormais" sexuais e de gênero também têm sido patrulhados em seu próprio direito de existir como tais.

Por isso apostamos na escuta como uma das chaves para o respeito à diversidade sexual e de gênero na atenção básica, e os corpos LGBTT precisam ser reconhecidos como usuários ativos da ESF. O que estamos falando é que, em mais de trina anos de reorganização sanitária nos territórios e expansão da ESF, não conseguimos que as populações LGBTT fossem efetivamente assistidas nos serviços de saúde, principalmente por parte das profissionais de saúde. Os discursos mostraram como as populações LGBTT são invisibilizadas em suas possibilidades de expressões, aparições e participações, e, já que escapam às normalidades do sexo e do gênero, ficam no lugar do "controle", da "verificação" e do "exame" de suas abjeções. Os jalecos brancos parecem ser como um escudo, utilizados na tentativa de se afastar desses corpos que carregam bandeiras, estigmas e proibições. 


\section{Colaboradores}

Todos os autores contribuíram igualmente em todas as etapas de construção do manuscrito.

\section{Referências}

1. Grupo Gay da Bahia. Mortes violentas de LGBT no Brasil - Relatório 2017 [Internet]. [acessado $2019 \mathrm{mar}$ 20]. Disponível em: https://homofobiamata.files.wordpress.com/2017/12/relatorio-2081.pdf.

2. Instituto de Pesquisa Econômica Aplicada (IPEA). Fórum Brasileiro de Segurança Pública. Atlas da Violência [Internet]. Brasília, Rio de Janeiro: IPEA; 2019. [acessado 2019 mar 23]. Disponível em: https:// www.ipea.gov.br/atlasviolencia/arquivos/downloads/ 6537-atlas2019.pdf

3. Ferreira BO, Bonan C. Abrindo os armários do acesso e da qualidade: uma revisão integrativa sobre assistência à saúde das populações LGBTT. Cien Saude Colet 2020; 25(5):1765-1778.

4. Snyder BK, Burack GD, Petrova A. LGBTQ youth's perceptions of primary care. Clinical Pediatric 2017; 56(1):443-450.

5. Popadiuk GS, Oliveira DC, Signorelli MC. A Política Nacional de Saúde Integral de Lésbicas, Gays, Bissexuais e Transgêneros (LGBT) e o acesso ao Processo Transexualizador no Sistema Único de Saúde (SUS):avanços e desafios. Cien Saude Colet 2017; 22(5):1509-1520.

6. Ferreira BO, Pedrosa JIS, Nascimento EF. Diversidade de Gênero e Acesso ao Sistema Único de Saúde. Rev Bras Proç Saude 2017; 31(1):1-10.

7. Brasil. Ministério da Saúde (MS). Secretaria de Atenção à Saúde. Departamento de Atenção Básica. $\mathrm{Ca}$ derno de Atenção Básica, no 26 - Saúde Sexual e Saúde Reprodutiva. Brasília: MS; 2010.

8. Brasil. Ministério da Saúde (MS). Portaria no 2.836, de 1 de dezembro de 2011. Institui, no âmbito do Sistema Único de Saúde (SUS), a Política Nacional de Saúde Integral de Lésbicas, Gays, Bissexuais, Travestis e Transexuais (Política Nacional de Saúde Integral LGBT). Diário Oficial da União; 2011.

9. Piauí. Fundação Municipal de Saúde de Teresina [Internet]. [acessado 2019 mar 23]. Disponível em: http://fms.teresina.pi.gov.br/system/downloads/ docs/140/original_original_guia-de-atencao-basica-da-fundacao-municipal-de-saude-de-teresina. pdf? 1531828371

10. Campos GWS. SUS: o que e como fazer? Cien Saude Colet 2018; 23(6):1707-1714.

11. Melo EA, Mendonça MHM, Oliveira JR, Andrade GCL. Mudanças na Política Nacional de Atenção Básica: entre retrocessos e desafios. Saude Debate 2018; 42(esp. 1):38-51.

12. Bauer MW, Gaskell G. Pesquisa qualitativa com texto, imagem e som: um manual prático. Petrópolis: Vozes; 2002.

13. Minayo MCS. A amostragem e saturação em pesquisa qualitativa: consensos e controvérsias. Rev Pesq Quali 2017; 5(7):1-12.

14. Trad LAB. Grupos focais: conceitos, procedimentos e reflexões baseadas em experiências com o uso da técnica em pesquisas de saúde. Physis 2009; 19(3):777796.

15. Gomes R, Mendonça EA. A representação e a experiência da doença: princípio para a pesquisa qualitativa em saúde. In: Minayo MCS, Deslandes SF, organizadores. Caminhos do pensamento: epistemologia e método. Rio de Janeiro: Fiocruz; 2002. 
16. Giovanella L, Fleury S. Universalidade da Atenção à Saúde: acesso como categoria de análise. In: Eibenschutz C, organizadora. Política de Saúde: o público e o privado. Rio de Janeiro: Fiocruz; 1996.

17. Barbosa MIS, Bosi MLM. Vínculo: um conceito problemático no campo da Saúde Coletiva. Physis 2017; 27(4):1003-1022.

18. Butler J. Problemas do gênero: Feminismo e subversão da identidade. Rio de Janeiro: Civilização Brasileira; 2017.

19. Rufino AC, Madeiro A, Trinidad AS, Rodrigues SR, Freitas I. Disclosure of Sexual Orientation Among Women Who Have Sex with Women During Gynecological Care: A Qualitative Study in Brazil. J Sex Med 2018; 15(7):966-973.

20. Barros FPC, Sousa MF. Equidade: seus conceitos, significações e implicações para o SUS. Saude Soc 2016; 25(1):9-18.

21. Minayo MCS. Violência e saúde. Rio de Janeiro: Editora Fiocruz; 2006.

22. Arruzza C, Bhattacharya T, Fraser N. Feminismo para os 99\%: um manifesto. São Paulo: Boitempo; 2019.

23. Lima ED, Oliveira Filho P. Discurso e identidade: a construção discursiva do Nordeste na mídia paraibana. Rev Psicol Política 2015; 15(34):497-514.

24. Silva ALR, Finkle MMPR. O. Representações sociais de trabalhadores da atenção básica à saúde sobre pessoas LGBT. Trab Educ Saude 2019; 17(2):e0019730.

25. Bourdieu P. O senso prático. Petrópolis: Vozes; 2009.

Artigo apresentado em 07/08/2020

Aprovado em 26/02/2021

Versão final apresentada em 28/02/2021

Editores-chefes: Romeu Gomes, Antônio Augusto Moura da Silva 